Article

\title{
The Effect of Pharmaceutical Excipients for Applying to Spray-Dried Omega-3 Powder
}

\author{
Chan-Joo Hwang ${ }^{\dagger} \ddagger$, Young-Guk Na ${ }^{+}$, Hyun Wook Huh, MinKi Kim, Hong-Ki Lee and \\ Cheong-Weon Cho* \\ College of Pharmacy and Institute of Drug Research \& Development, Chungnam National University, \\ 99 Daehak-ro, Yuseong-gu, Daejeon 34134, Korea; mistist_30@naver.com (C.-J.H.); \\ youngguk@cnu.ac.kr (Y.-G.N.); hhw3573@nate.com (H.W.H.); zkzkang@naver.com (M.K.); \\ dvmlhk@gmail.com (H.-K.L.) \\ * Correspondence: chocw@cnu.ac.kr; Tel.: +82-42-821-5934 \\ + Two authors equally contributed to this work. \\ $\ddagger$ Present affiliation: R\&D Center, Daewoong Pharmaceutical Company, Yongin 449-814, Korea.
}

Received: 26 February 2019; Accepted: 16 March 2019; Published: 20 March 2019

check for updates

\begin{abstract}
Omega-3 fatty acid plays a role in protecting cells in the human body, maintaining the structure of the cell, and helping smooth metabolism. Also, it inhibits the formation of blood clotting and is effective in enhancing the formation of bone. However, the instability due to fatty acid oxidation and a fishy smell are the reasons it is avoided by people. In this study, we tried to obtain the omega-3 powder through spray-drying method using a variety of binders and surfactants for improving the limit of omega-3 fatty acid. First of all, an olive oil was used instead of omega-3 for optimization of the preparation of spray-dried omega-3 powder. Through the screening of binders and surfactants, $\gamma$-cyclodextrin and hydrogenated lecithin were chosen as a binder and a surfactant, respectively. Omega-3-loaded spray-dried powder was obtained, eventually. The morphology of omega-3-loaded spray-dried powder was spherical of $310 \mathrm{~nm}$ and the DHA amount was $98 \%$. This study suggested that the transformation of omega-3 fatty acid into solid state by spray-drying using a binder and a surfactant was successively performed.
\end{abstract}

Keywords: omega-3 fatty acid; spray drying; powder; pharmaceutical excipients

\section{Introduction}

Solid formulations are highly preferred in the pharmaceutical market because they easy to administer and have superior stability during storage. On the other hand, the liquid formulation is easily hydrolyzed and oxidized. Oil components such as fatty acid were filled into soft capsules and marketed. However, these soft capsules have still some problems by leaking. In particular, the omega-3 is an unsaturated fatty acid, which is composed of DHA (docosahexaenoic acid) and EPA (eicosapentaenic acid). DHA or EPA is composed of 20 or 22 carbon atoms with five or six double bonds and has a first double bond at the third methyl group from the $\omega$ side. EPA was formed from $\alpha$-linolenic acid (18:3 $\omega$-3) and DHA was obtained from EPA. $\alpha$-Linolenic acid was synthesized from linoleic acid (18:2 $\omega-6)$. Both $\alpha$-linolenic acid and linoleic acid have been regarded as essential fatty acids because they cannot be synthesized in the body. However, the efficiency of the $\alpha$-linolenic acid converted to EPA and DHA in adults is low with about $10-15 \%$, about 3-6\% in children [1]. It has been reported that intake of EPA and DHA may help to improve blood circulation, stimulate the breakdown of fibrin, and reduce blood pressure and blood triglyceride levels [2-7]. Therefore, customers had better take foods containing a lot of DHA and EPA in order to expect the effect of EPA and DHA. Long chain polyunsaturated fatty acids such as omega-3 are easily oxidized, leading to instability. 
This limitation yields their shelf-life only 6 months, when stored at $4{ }^{\circ} \mathrm{C}$ in a closed container under nitrogen [8].

So, there are many advantages as follows: firstly, possible reduction in the volume of administration (e.g., converting a liquid emulsions or suspensions containing more than $50 \%$ liquid into the dry state that can be filled / processed into single capsule or tablet unit) if omega-3 changes into solid forms. Secondly, enhanced precise dosing (e.g., packing of the whole dose into capsules/tablets provides more accurate and precise dosing in comparison to administering a prescribed volume of a suspension using a syringe or spoon). Thirdly, ease of transfer and storage (i.e., liquid formulations are bulky and typically prone to instability and microbial contamination). Fourthly, better patient compliance (i.e., it is generally preferred by adult patients to administer capsules/tablets rather than a liquid formulation) [2,4-6]. As well as, the herbal extracts, for example, mulberry extracts need to be solidified for the stability. The general approaches for solidification include physical adsorption onto solid carriers, spray drying, freeze-drying or lyophilization, rotary evaporation, melt extrusion-spheronization and melt granulation [9]. Omega-3 fatty acids are essential nutrients that are important in preventing and managing heart disease, which are in a class of medications called antilipidemic or lipid-regulating agents. Therefore, authors focused on the preparation and characterization of spray-dried omega-3 powder for the combination with other medications. First of all, the optimization was performed using a cheap olive oil instead of an expensive omega- 3 for the preparation of a spray-dried powder in this study.

\section{Materials and Methods}

\subsection{Materials}

Omega-3 fatty acid containing EPA $(460 \mathrm{mg} / \mathrm{mL})$ and DHA $(380 \mathrm{mg} / \mathrm{mL})$ were received from Kuhnil Pharmaceutical co., Ltd. (Seoul, Korea). Edible olive oil was purchased from Sempio Co., Ltd. (Seoul, Korea). Methyl cellulose (MC) was purchased Junsei Chemical Co., Ltd. (Tokyo, Japan). Hydropropylmethylcellulose (HPMC, Metolose ${ }^{\circledR}$ 60SH-50) was received from Richwood trading Co., Ltd. (Pyeongtaek, Korea). Gelatin type A (G1890), type B (G9391), hydrogenated lecithin and PEG-40 glyceryl monostearate were purchased from Sigma-Aldrich Co., Ltd. Korea (Yongin, Korea). $\alpha, \beta$, and $\gamma$-cyclodextrin $(\alpha, \beta$, and $\gamma$-CD) was provided from Whawon Pharm Co., Ltd. (Seoul, Korea). Polyvinylpyrrolidone (PVP, Kollidone ${ }^{\circledR} \mathrm{K} 30$ ) and poloxamer 188 (Lutrol ${ }^{\circledR} \mathrm{F} 68$ ) was received from BASF Co., Ltd. Korea (Seoul, Korea). All other excipients were used as received without further purification.

\subsection{Preparation of Spray-Dried Powder}

The emulsifier solution (ES) was prepared by dissolving surfactant in distilled water (DW). The adsorbent solution (AS) was prepared by dispersing the pharmaceutical excipients such as MC, HPMC, PVP, $\alpha, \beta, \gamma-C D$, gelatin A and gelatin B in ES and sonicated for 10 min with an amplitude of $85 \%, 130$ watt, $20 \mathrm{kHz}$ frequency, and pulse cycle of $15 \mathrm{~s} / 8 \mathrm{~s}$ to disperse the adsorbent. The first emulsion (FE) was prepared by adding an olive oil to ES, which was sonicated until the oil droplet was disappeared by the same condition with the preparation of AS. The second emulsion (SE) was prepared by mixing AS with FE. The SE containing 50\% $(w / w)$ olive oil was stored in the dark until spray drying. Spray drying was conducted at a flow rate $1.0 \mathrm{~L} / \mathrm{h}, 150{ }^{\circ} \mathrm{C}$ inlet temperature and $70 \sim 75{ }^{\circ} \mathrm{C}$ outlet temperature using spray dryer with a single nozzle atomizer (SD-1000, Eyela, Japan) (Scheme 1). The spray-dried powder was stored at $-20^{\circ} \mathrm{C}$ until use. MC, HPMC, and PVP were used for amphiphilic polymers. $\alpha, \beta$, and $\gamma$-CD were used for polysaccharide-based material. Gelatin type $\mathrm{A}$ and $\mathrm{B}$ were used based on the characteristics of the film formation of gelatin. On the other hand, poloxamer 188, hydrogenated lecithin or PEG-40 glyceryl monostearate as an amphiphilic surfactant. 


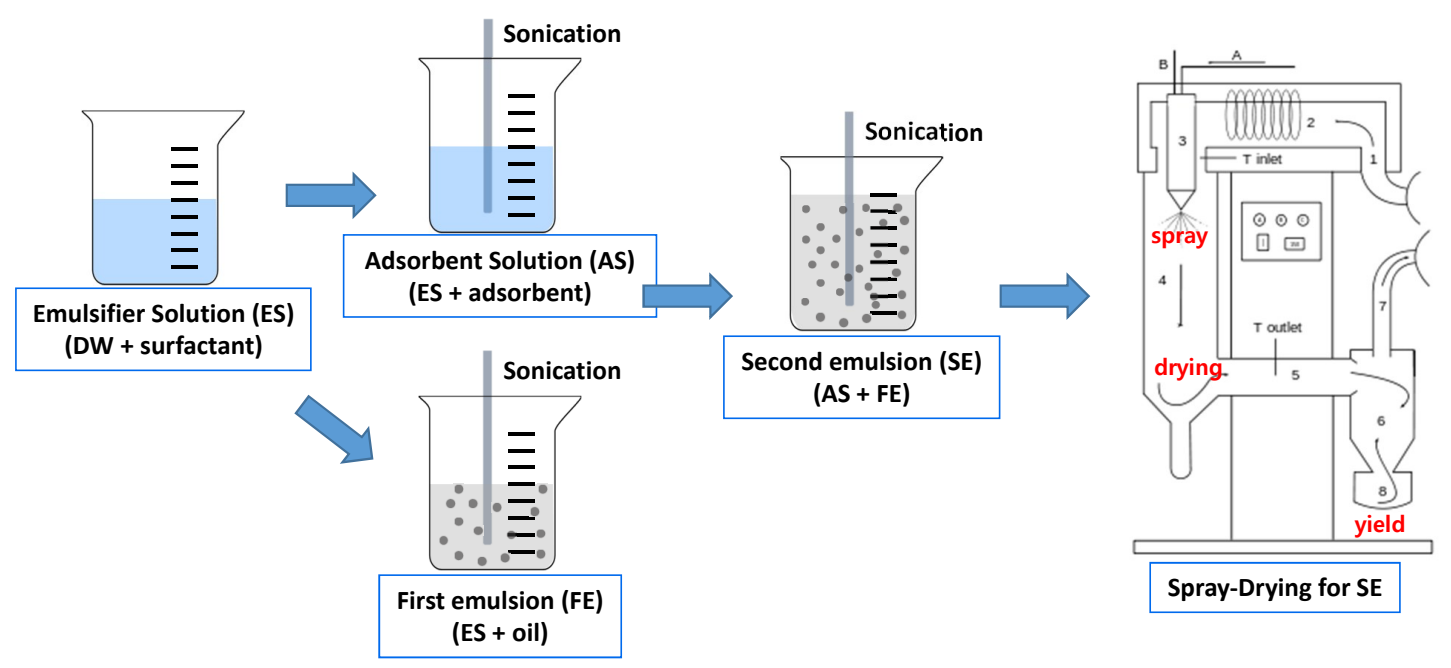

Scheme 1. The spray drying process for the preparation of oil powder.

\subsection{Determination of Particle Size of Spray-Dried Powder}

The particle size of SE before spray-drying and the reconstituted emulsion (RE) after spray-drying was determined by ELS-8000 laser scattering particle size analyzer (Otsuka Electronics Co., Osaka, Japan), which measures particle size and particle-size distribution based on the dynamic light-scattering method. The primary results from dynamic light scattering (DLS) systems are typically reported as an intensity distribution. Key values included in DLS-based specifications are the intensity-weighted average (often called the " $\mathrm{z}$ average") and the polydispersity index (PI), which quantifies distribution width. The SE was diluted with DW enough to prevent multiple scattering effects. For analysis of RE, $0.1 \mathrm{~g}$ of spray-dried powder was dispersed in $10 \mathrm{~mL}$ of DW, and vortexed for $5 \mathrm{~min}$. Then, RE was diluted with DW enough to prevent multiple scattering effects.

\subsection{Determination of Moisture Amount, Free Oil, Encapsulated Oil, and Total Oil of Spray-Dried Powder}

Approximately $3 \mathrm{~g}$ of spray-dried powder was placed in an aluminum plate and the moisture amount was determined using moisture determinant balance (FD-600, Kett electric Lab., Tokyo, Japan). All determination was repeated three times. Extraction of free oil, encapsulated oil, and total oil from spray-dried oil powder was followed by modification of publication [10].

Ten $\mathrm{mL}$ of hexane was added to $1.0 \mathrm{~g}$ of spray-dried oil powder. The mixture was mixed using vortex mixer for $1 \mathrm{~min}$ and was centrifuged at $4500 \mathrm{rpm}$ for $10 \mathrm{~min}$. Then, the supernatant was filtered using filter paper, and the filter paper washed with $10 \mathrm{~mL}$ of hexane. The residual hexane onto the filter paper was evaporated under nitrogen at $40^{\circ} \mathrm{C}$ and the filter paper was dried in $70{ }^{\circ} \mathrm{C}$. The amount of excess free oil was determined by measuring the filter paper, gravimetrically.

For encapsulated oil, $3 \mathrm{~mL}$ of water was added to $0.5 \mathrm{~g}$ of free oil-extracted powder and mixed using vortex mixer for $5 \mathrm{~min}$. Then, $10 \mathrm{~mL}$ of hexane/isopropanol $(3: 1 \mathrm{v} / \mathrm{v})$ was added to the mixture. The resulting mixture was shaken for 20 min using an automatic mixer, and then centrifuged for $10 \mathrm{~min}$. The upper organic phase was collected. Lower aqueous phase was re-extracted with $10 \mathrm{~mL}$ of hexane/isopropanol (3:1 $\mathrm{v} / \mathrm{v})$. The collected solution was filtered using filter paper, and solvent was evaporated under nitrogen at $40{ }^{\circ} \mathrm{C}$. After evaporation, the filter paper was dried at $70{ }^{\circ} \mathrm{C}$ oven. The amount of encapsulated oil was calculated by the difference between the free oil-extracted powder and the filter paper, gravimetrically.

For total oil, $3 \mathrm{~mL}$ of water was added to $0.5 \mathrm{~g}$ of spray-dried oil powder and mixed for $5 \mathrm{~min}$. Then, the procedure of extraction was conducted using the same method as mentioned above for extraction of encapsulated oil. 


\subsection{Scanning Electron Microscopy (SEM)}

A SEM (JEOL JSM-7500F, Thermo, Waltham, MA, USA) was used to observe and compare the morphology of spray-dried powder between different formulations. Samples were mounted on stubs using double stick carbon tape. A gold/palladium was then applied to the surface in a vacuum evaporator to make samples conductive and samples were coated. All samples were examined at an acceleration voltage of 1 to $5 \mathrm{kV}$. Photographs were taken at $2.0 \mathrm{k}, 4.0 \mathrm{k}$, and $10.0 \mathrm{k}$ magnification.

\subsection{Chromatography Condition}

The analysis of EPA and DHA was performed on a HP 6890 gas chromatograph (Agilent, Santa Clara, CA, USA) equipped with an autosampler and a flame ionization detector. The samples were analyzed on a HP-5 capillary column $(50 \mathrm{~mm} \times 0.32 \mathrm{~mm} \times 0.52 \mu \mathrm{m})$. Data collection was performed by the HP chemstation software. The temperature program was as follows: the oven temperature was held at $60^{\circ} \mathrm{C}$ for $1 \mathrm{~min}$, ramped to $160^{\circ} \mathrm{C}$ at $25^{\circ} \mathrm{C} / \mathrm{min}$, held at $160^{\circ} \mathrm{C}$ for $28 \mathrm{~min}$, increased to $190{ }^{\circ} \mathrm{C}$ at $25^{\circ} \mathrm{C} / \mathrm{min}$, held at $190{ }^{\circ} \mathrm{C}$ for $17 \mathrm{~min}$, ramped to $220^{\circ} \mathrm{C}$ at $25^{\circ} \mathrm{C} / \mathrm{min}$ and held at $220^{\circ} \mathrm{C}$ for $10 \mathrm{~min}$. Direct on-column injection was used. The injector port temperature was ramped instantly from 50 to $250{ }^{\circ} \mathrm{C}$ and the detector temperature was $250{ }^{\circ} \mathrm{C}$. The carrier gas was ultrapure helium at a pressure of $82 \mathrm{kPa}$. Analysis time was $60 \mathrm{~min}$. Analysis method and sample preparation were followed by the method of Araujo et al. [11]. Briefly, $50 \mu \mathrm{L}$ (or $50 \mathrm{mg}$ ) of sample was mixed with $2 \mathrm{~mL}$ of $\mathrm{BF} 3 / \mathrm{CH}_{3} \mathrm{OH}$. And the mixture was heated at $100^{\circ} \mathrm{C}$ for $1 \mathrm{~h}$ and cooled down at room temperature. Then, $1 \mathrm{~mL}$ of hexane and $2 \mathrm{~mL}$ of DW were added, vortexed for $15 \mathrm{~s}$, centrifuged at $3000 \mathrm{rpm}$ for $2 \mathrm{~min}$ and the methyl esters were extracted from the upper hexane phase.

\subsection{Statistical Analysis}

The obtained data were evaluated by one way-ANOVA, $p<0.05$ was considered as the significant level.

\section{Results}

\subsection{Preparation of Spray-Dried Emulsion Powder}

Recently, powders with $30 \%, 35 \%$ and $40 \%(w / w)$ load of triglyceride oil and $25 \%, 30 \%$ and $40 \%$ $(w / w)$ load of ethyl ester oil, respectively, were prepared to further explore how much fish oil can be included in a direct compression grade powder. All powders with up to $35 \%(w / w)$ triglyceride oil and 30\% $(w / w)$ ethyl ester oil, respectively were dried by spray granulation [12].

Amphiphilic polymers such as poloxamers, HPMC, carboxymethylcellulose sodium and PVP had many applications as emulsifiers and solid carriers $[8,13,14]$. On the other hand, owing to gelatin's film-forming properties, gelatin had been used to encapsulate fish oils and oily vitamin in gelatin beadlets using coacervation technique, which can then be handled as a powdered formulation. Polysaccharide (or carbohydrate)-based excipients had a long history of applications in the food and pharmaceutical industries as sweeteners, coating agents, bulking agents, viscosity-enhancers, tablet/capsule binders, diluents, and direct compression agents, which are low molecular weight mannitol, sorbitol, sucrose, lactose, trehalose, and the higher molecular weight maltodextrins, cyclodextrins, dextrins, gum acacia and starch sodium octenyl succinate, etc. [15]. Twenty-eight spray dried olive oil powder was obtained.

According to the surfactants, 28 formulations were prepared using olive oil as a substitute of omega-3. In detail, various pharmaceutical excipients such as MC, HPMC, PVP, gelatin A, gelatin B, $\alpha-C D, \beta-C D$, and $\gamma-C D$ were used with fixing poloxamer 188 as a surfactant for spray-dried olive oil powder. The formulations were numbered from P1 to P8 according to the order of pharmaceutical excipients. The spray-dried olive oil powder using pharmaceutical excipients such as MC, HPMC, PVP, gelatin A, gelatin $B, \alpha-C D, \beta-C D$, and $\gamma-C D$ was prepared with a fixation of hydrogenated lecithin as a surfactant. The formulations were numbered from P11 to P18 according to the order 
of pharmaceutical excipients. PEG40 glyceryl monostearate as surfactant was used for spray-dried olive oil powder using pharmaceutical excipients such as MC, HPMC, PVP, gelatin A, gelatin B, $\alpha-C D, \beta-C D$, and $\gamma-C D$. The formulations were numbered from P21 to P28 according to the order of pharmaceutical excipients. The amount of pharmaceutical excipients or surfactant was $6.8 \mathrm{~g}$ or $2.5 \mathrm{~g}$ over all formulations, respectively. The olive oil was set to $50 \%$ in spray-dried powder. Interestingly, in P13, P14, P15, P23, P24, and P25, spray-dried powder was not obtained. So, the physicochemical characterizations of $\mathrm{P} 13,14,15,23,24$ and 25 were not carried out. There was a publication that the adsorption of polyvinylalcohol spontaneously occurs from aqueous suspensions onto the surface of hydrophobic drug and had been affected by \% hydrolysis and molecular mass [16]. It could be suggested that spray-dried powder was not obtained through the strong adsorption when more viscous excipients such as PVP, gelatin A and gelatin B interact with more hydrophobic surfactants such as hydrogenated lecithin or PEG40 glyceryl monostearate during spray-drying step.

\subsection{The Particle Size of Spray-Dried Powder}

The particle size of SE before spray-drying and RE after spray-drying was shown in Table 1. The droplet sizes of SE and RE were several hundred nanometers. Most formulations showed higher droplet size of RE than that of SE except for P4, P16 and P18. P4, P8, P16, P18, and P21 showed $80 \sim 120 \%$.

Table 1. The particle size of second emulsion (SE) before spray drying and reconstituted emulsion (RE) of olive oil powder after spray drying $(\mathrm{n}=3)$.

\begin{tabular}{ccc}
\hline Formular & SE $(\mathbf{n m})$ & $\mathbf{R E}(\mathbf{n m})$ \\
\hline P1 & $488.85 \pm 30.8$ & $600.85 \pm 76.6$ \\
P2 & $396.85 \pm 3.0$ & $483.95 \pm 65.3$ \\
P3 & $252.40 \pm 11.5$ & $469.55 \pm 76.2$ \\
P4 & $711.70 \pm 168.1$ & $660.85 \pm 171.8$ \\
P5 & $214.35 \pm 3.5$ & $473.50 \pm 141.8$ \\
P6 & $250.80 \pm 8.9$ & $360.40 \pm 50.3$ \\
P7 & $268.95 \pm 13.4$ & $374.75 \pm 155.6$ \\
P8 & $258.95 \pm 7.3$ & $293.35 \pm 19.0$ \\
P11 & $296.47 \pm 22.8$ & $472.73 \pm 17.0$ \\
P12 & $336.93 \pm 37.8$ & $472.97 \pm 16.0$ \\
P16 & $257.00 \pm 8.3$ & $216.57 \pm 2.5$ \\
P17 & $237.40 \pm 10.1$ & $330.20 \pm 38.2$ \\
P18 & $280.57 \pm 17.8$ & $246.20 \pm 19.9$ \\
P21 & $284.87 \pm 5.1$ & $342.13 \pm 10.9$ \\
P22 & $285.97 \pm 2.0$ & $405.60 \pm 9.1$ \\
P26 & $540.10 \pm 39.5$ & $847.70 \pm 58.3$ \\
P27 & $354.87 \pm 3.3$ & $695.83 \pm 108.0$ \\
P28 & $339.23 \pm 24.1$ & $712.20 \pm 72.6$ \\
\hline
\end{tabular}

\subsection{Determination of Moisture Content, Free Oil, Encapsulated Oil, and Total Oil}

The moisture content, free oil, encapsulated oil, and total oil of formulations according to binder and surfactant were presented in Table 2. When poloxamer 188 was used as a surfactant, the moisture (\%) of spray-dried oil powder (P1 P8) was from 3.50 to $8.30 \%$. When hydrogenated lecithin was used as a surfactant, the moisture (\%) of spray-dried oil powder (P11 P18) was from 2.85 to $4.00 \%$. When PEG40 glyceryl monostearate was used as a surfactant, the moisture (\%) of spray-dried oil powder (P21 P28) was from 3.80 to $6.45 \%$. Most formulations showed about $10 \%$ of encapsulated oil. Generally, small difference between droplet size of SE and RE indicated well re-dispersibility and stability. The moisture (\%) of spray-dried oil powder is $2.85 \sim 8.30 \%$ over the formulations. When hydrogenated lecithin was used as a surfactant, the encapsulated oil in spray-dried oil powder was more detected than in the group of poloxamer 188 or PEG40 glyceryl stearate as a surfactant. 
Table 2. The comparison of spray-dried olive oil powder by determining the moisture amount and oil amount (free oil, encapsulated oil and total oil) $(n=3)$.

\begin{tabular}{ccccc}
\hline Formular & Moisture (\%) & Free Oil (g/100 g) & Encapsulated Oil (g/100 g) & Total Oil (g/100 g) \\
\hline P1 & $5.10 \pm 0.70$ & $48.28 \pm 1.42$ & $10.85 \pm 3.82$ & $66.42 \pm 1.33$ \\
P2 & $3.50 \pm 0.14$ & $36.66 \pm 3.26$ & $10.30 \pm 0.66$ & $56.41 \pm 2.47$ \\
P3 & $5.05 \pm 0.49$ & $39.44 \pm 3.48$ & $5.92 \pm 1.05$ & $58.30 \pm 0.30$ \\
P4 & $8.30 \pm 2.12$ & $40.00 \pm 2.99$ & $7.79 \pm 1.18$ & $60.75 \pm 0.83$ \\
P5 & $6.20 \pm 1.13$ & $39.36 \pm 0.90$ & $9.24 \pm 2.65$ & $62.42 \pm 0.23$ \\
P6 & $3.55 \pm 0.21$ & $38.87 \pm 2.21$ & $13.74 \pm 1.98$ & $58.33 \pm 3.01$ \\
P7 & $4.10 \pm 0.99$ & $39.35 \pm 1.60$ & $9.66 \pm 1.36$ & $59.37 \pm 2.29$ \\
P8 & $4.98 \pm 1.20$ & $37.96 \pm 2.97$ & $8.66 \pm 3.28$ & $56.02 \pm 5.89$ \\
\hline P11 & $2.90 \pm 0.14$ & $58.04 \pm 1.53$ & $17.33 \pm 3.86$ & $56.04 \pm 2.90$ \\
P12 & $2.85 \pm 0.07$ & $47.80 \pm 0.37$ & $11.36 \pm 3.64$ & $58.49 \pm 7.90$ \\
P16 & $3.75 \pm 0.21$ & $52.59 \pm 0.97$ & $10.27 \pm 2.64$ & $54.45 \pm 1.79$ \\
P17 & $3.75 \pm 0.49$ & $48.04 \pm 1.44$ & $10.86 \pm 2.02$ & $54.78 \pm 2.93$ \\
P18 & $4.00 \pm 0.14$ & $49.55 \pm 0.63$ & $10.18 \pm 2.95$ & $56.96 \pm 4.26$ \\
\hline P21 & $5.90 \pm 1.70$ & $57.78 \pm 0.42$ & $11.77 \pm 0.83$ & $67.43 \pm 4.52$ \\
P22 & $4.75 \pm 1.91$ & $52.36 \pm 0.44$ & $10.22 \pm 0.62$ & $56.26 \pm 1.94$ \\
P26 & $6.45 \pm 1.20$ & $56.63 \pm 5.43$ & $9.18 \pm 0.26$ & $59.69 \pm 3.84$ \\
P27 & $3.80 \pm 0.57$ & $62.55 \pm 2.06$ & $8.57 \pm 1.58$ & $65.79 \pm 6.57$ \\
P28 & $5.50 \pm 0.85$ & $65.68 \pm 1.69$ & $7.73 \pm 0.53$ & $67.51 \pm 2.03$ \\
\hline
\end{tabular}

\subsection{SEM Image}

Figure 1 showed the morphology of P8, P16, P18 and P21, respectively. P8 and P16 looked like forming aggregates. Maybe, it was due to incomplete evaporation or oil leakage. P18 showed the spherical shape with many pores but its surface was smooth. P21 seemed like a wrinkled sphere and had many pores at surface, which made the particles stick together. These results are consistent with publications, which detected wrinkles on the surface of the particles in spray-dried powder $[10,16]$. SEM image of spray-dried oil powder looked like forming aggregates due to incomplete evaporation or oil leakage. It was reported that wrinkles were attributed to the results of mechanical stresses induced by uneven drying at different parts of the droplets during the early stages of drying [17], to the movement of the moisture during the surface drying period [18], and to the effect of a surface tension-driven viscous flow [17]. Wrinkles of the particle followed by an excipient expansion may induce changes in the size of particles and causes the wall material to break [19]. Therefore, P18 was chosen for further study, which was confirmed using a software of Design Expert ${ }^{\circledR} 11$ (Tables S1-S3). The key parameters to obtain the optimized formulation are SE, RE and morphology (Figure S1).

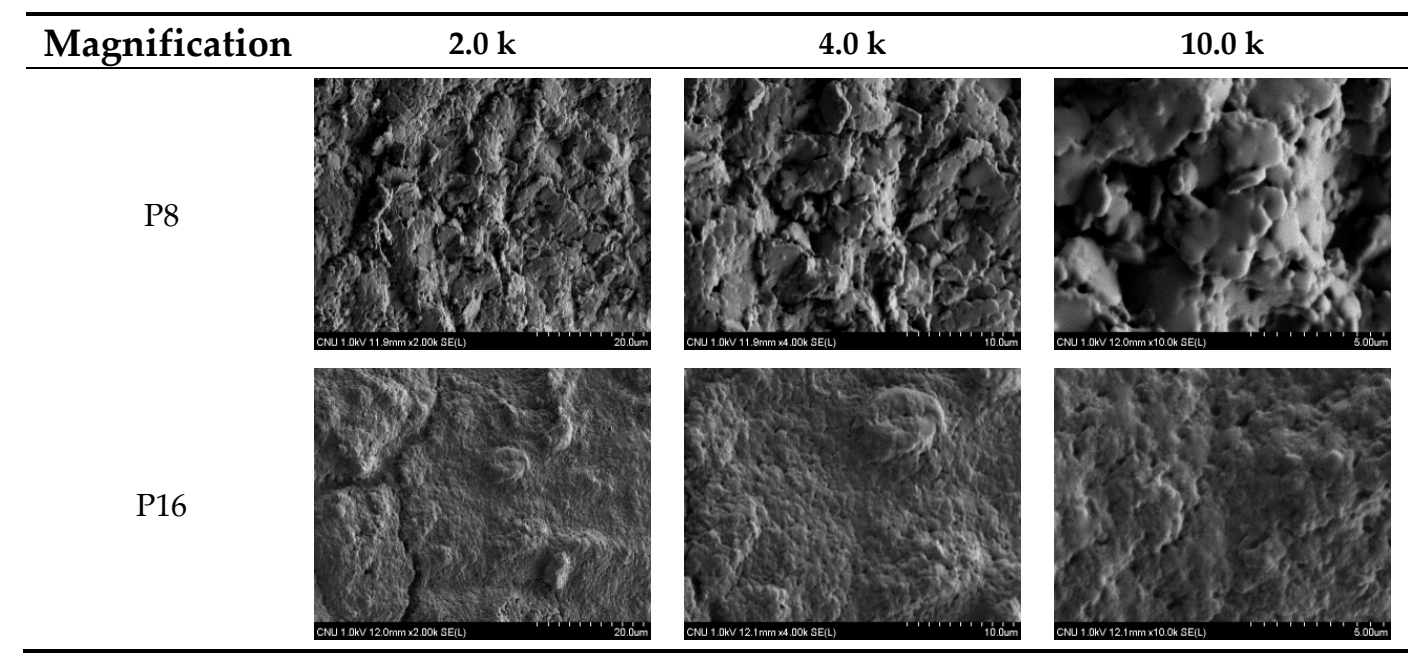

Figure 1. Cont. 


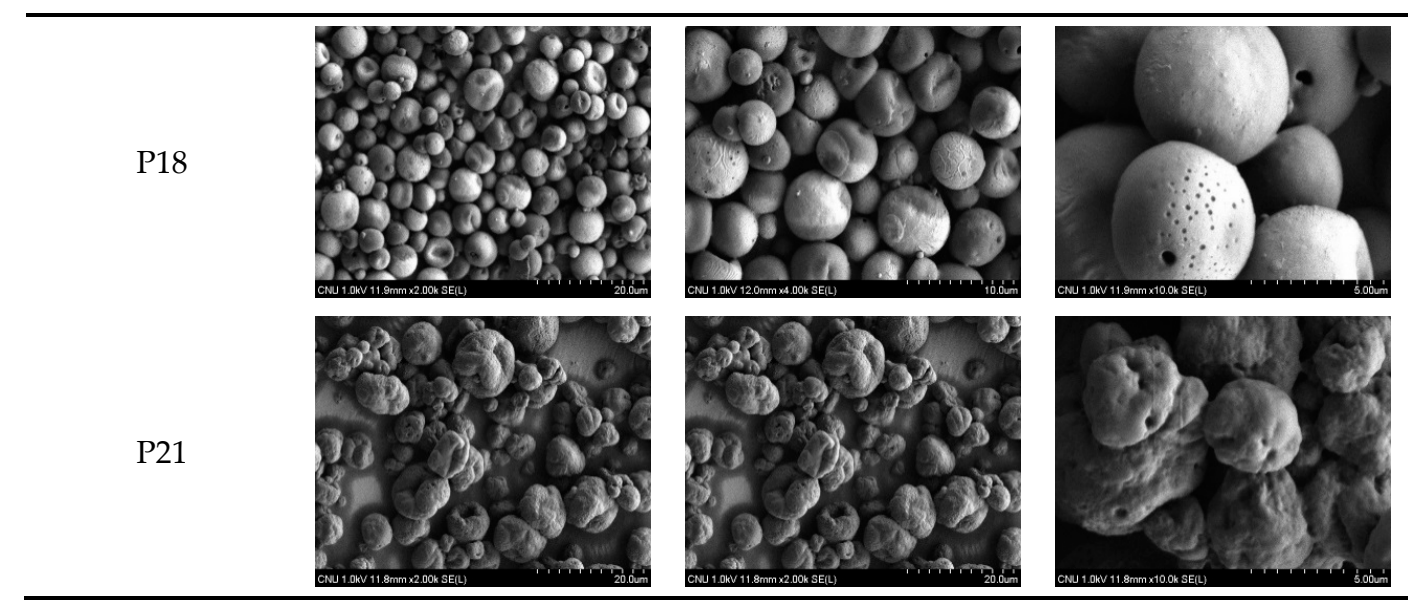

Figure 1. SEM image of spray-dried olive oil powder, P8, P16, P18, and P21. P18 showed the spherical shape with many pores but its surface was smooth.

\subsection{Characteristics of Spray-Dried Powder According to Ratio of Encapsulant To Surfactant}

The formulations were varied from P18-1 to P18-5 according to ratio of $\gamma$-CD to hydrogenated lecithin. On the other hand, the operating conditions for spray-drying was varied. P18-6 was diluted with twice volume of water compared with P18-4. P18-6 and P18-7 was prepared to confirm the effects of inlet and outlet temperature. P18-8 was prepared to check the effect of atomization pressure (Table 3).

Table 3. Various spray drying condition for spray-dried olive oil powder using $\gamma$-CD and hydrogenated lecithin.

\begin{tabular}{ccccccccc}
\hline Formular & $\begin{array}{c}\text { Inlet Temp. } \\
\left({ }^{\circ} \mathbf{C}\right)\end{array}$ & $\begin{array}{c}\text { Outlet Temp. } \\
\left({ }^{\circ} \mathbf{C}\right)\end{array}$ & $\begin{array}{c}\text { Atomization } \\
\text { Pressure }\end{array}$ & $\begin{array}{c}\text { Olive } \\
\text { Oil }(\mathbf{g})\end{array}$ & $\begin{array}{c}\text { DW } \\
(\mathbf{m L})\end{array}$ & $\begin{array}{c}\boldsymbol{\gamma} \text {-CD } \\
(\mathbf{g})\end{array}$ & $\begin{array}{c}\text { Hydrogenated } \\
\text { Lecithin }(\mathbf{g})\end{array}$ & $\begin{array}{c}\text { Total } \\
(\mathbf{g})\end{array}$ \\
\hline P18-1 & 180 & $85-90$ & 15 & 9.3 & 200 & 4.8 & 4.5 & 18.6 \\
P18-2 & 180 & $85-90$ & 15 & 9.3 & 200 & 5.8 & 3.5 & 18.6 \\
P18-3 & 180 & $85-90$ & 15 & 9.3 & 200 & 6.8 & 2.5 & 18.6 \\
P18-4 & 180 & $85-90$ & 15 & 9.3 & 200 & 7.8 & 1.5 & 18.6 \\
P18-5 & 180 & $85-90$ & 15 & 9.3 & 200 & 8.8 & 0.5 & 18.6 \\
P18-6 & 180 & $85-90$ & 15 & 9.3 & 400 & 7.8 & 1.5 & 18.6 \\
P18-7 & 150 & $70-75$ & 15 & 9.3 & 400 & 7.8 & 1.5 & 18.6 \\
P18-8 & 150 & $70-75$ & 10 & 9.3 & 400 & 7.8 & 1.5 & 18.6 \\
\hline
\end{tabular}

\subsection{Determination of Particle Size, Moisture and Free Oil, Encapsulated Oil, and Total Oil}

The moisture (\%) of formulations was about $4 \%$ and there is no significant difference between formulations. The diluted emulsion formulation (P18-6) had lower moisture content than that of P18-4. The droplet size of SE and RE was ranged from 300 to $400 \mathrm{~nm}$. Droplet size of RE increased than droplet of SE. But, there was no difference significantly between SE and RE under the various spray-drying operating condition. The content of free oil was ranged from 30.33 to $42.23 \%$ (Table 4 ).

Table 4. The effect of various spray drying condition on moisture amount, particle size and oil amount (free oil, encapsulated oil and total oil) of spray-dried olive oil powder using $\gamma$-CD and hydrogenated lecithin $(n=3)$.

\begin{tabular}{ccccccc}
\hline Formular & $\begin{array}{c}\text { Moisture } \\
(\mathbf{\%})\end{array}$ & SE $(\mathbf{n m})$ & RE $(\mathbf{n m})$ & $\begin{array}{c}\text { Free Oil } \\
(\mathbf{g} / \mathbf{1 0 0} \mathbf{g})\end{array}$ & $\begin{array}{c}\text { Encapsulated } \\
\text { Oil } \mathbf{( g / 1 0 0} \mathbf{g})\end{array}$ & $\begin{array}{c}\text { Total Oil } \\
(\mathbf{g} / \mathbf{1 0 0} \mathbf{g})\end{array}$ \\
\hline $\mathrm{P} 18-1$ & $4.17 \pm 0.50$ & $337.17 \pm 8.32$ & $351.77 \pm 9.13$ & $42.23 \pm 0.03$ & $10.20 \pm 0.64$ & $56.95 \pm 0.70$ \\
$\mathrm{P} 18-2$ & $3.67 \pm 0.40$ & $281.70 \pm 1.93$ & $388.13 \pm 13.88$ & $39.30 \pm 4.60$ & $11.14 \pm 0.19$ & $54.63 \pm 2.11$ \\
P18-3 & $3.87 \pm 0.31$ & $305.13 \pm 3.45$ & $323.20 \pm 7.37$ & $37.98 \pm 4.67$ & $12.35 \pm 1.74$ & $52.84 \pm 3.52$ \\
P18-4 & $3.40 \pm 0.30$ & $341.80 \pm 4.95$ & $344.73 \pm 11.86$ & $35.33 \pm 1.21$ & $14.12 \pm 0.88$ & $52.10 \pm 1.52$ \\
P18-5 & $3.67 \pm 0.25$ & $352.77 \pm 24.8$ & $378.33 \pm 10.82$ & $33.67 \pm 0.07$ & $14.22 \pm 2.78$ & $51.58 \pm 1.85$ \\
\hline
\end{tabular}


Table 4. Cont

\begin{tabular}{ccccccc}
\hline Formular & $\begin{array}{c}\text { Moisture } \\
\mathbf{( \% )}\end{array}$ & SE (nm) & RE $(\mathbf{n m})$ & $\begin{array}{c}\text { Free Oil } \\
\mathbf{( g / 1 0 0} \mathbf{g})\end{array}$ & $\begin{array}{c}\text { Encapsulated } \\
\text { Oil } \mathbf{( g / 1 0 0} \mathbf{g})\end{array}$ & $\begin{array}{c}\text { Total Oil } \\
(\mathbf{g} / \mathbf{1 0 0} \mathbf{g})\end{array}$ \\
\hline $\mathrm{P} 18-6$ & $2.03 \pm 0.15$ & $355.83 \pm 21.1$ & $366.80 \pm 16.51$ & $32.53 \pm 2.20$ & $18.55 \pm 0.67$ & $52.77 \pm 0.94$ \\
P18-7 & $2.33 \pm 0.06$ & $354.93 \pm 6.21$ & $337.37 \pm 15.46$ & $30.33 \pm 0.83$ & $19.14 \pm 1.07$ & $51.89 \pm 0.93$ \\
P18-8 & $2.43 \pm 0.15$ & $328.37 \pm 19.5$ & $355.97 \pm 14.28$ & $29.21 \pm 0.66$ & $19.38 \pm 0.81$ & $52.44 \pm 1.30$ \\
\hline
\end{tabular}

\subsection{Characteristics of Omega-3 Fatty Acid Powder}

The morphology of P18-1 to P18-4 was dented sphere and they had many pores. However, P18-5 had excessively many dent with an irregular shape. There is no significant difference in morphology according to inlet temperature, outlet temperature and atomization pressure (Figure 2).

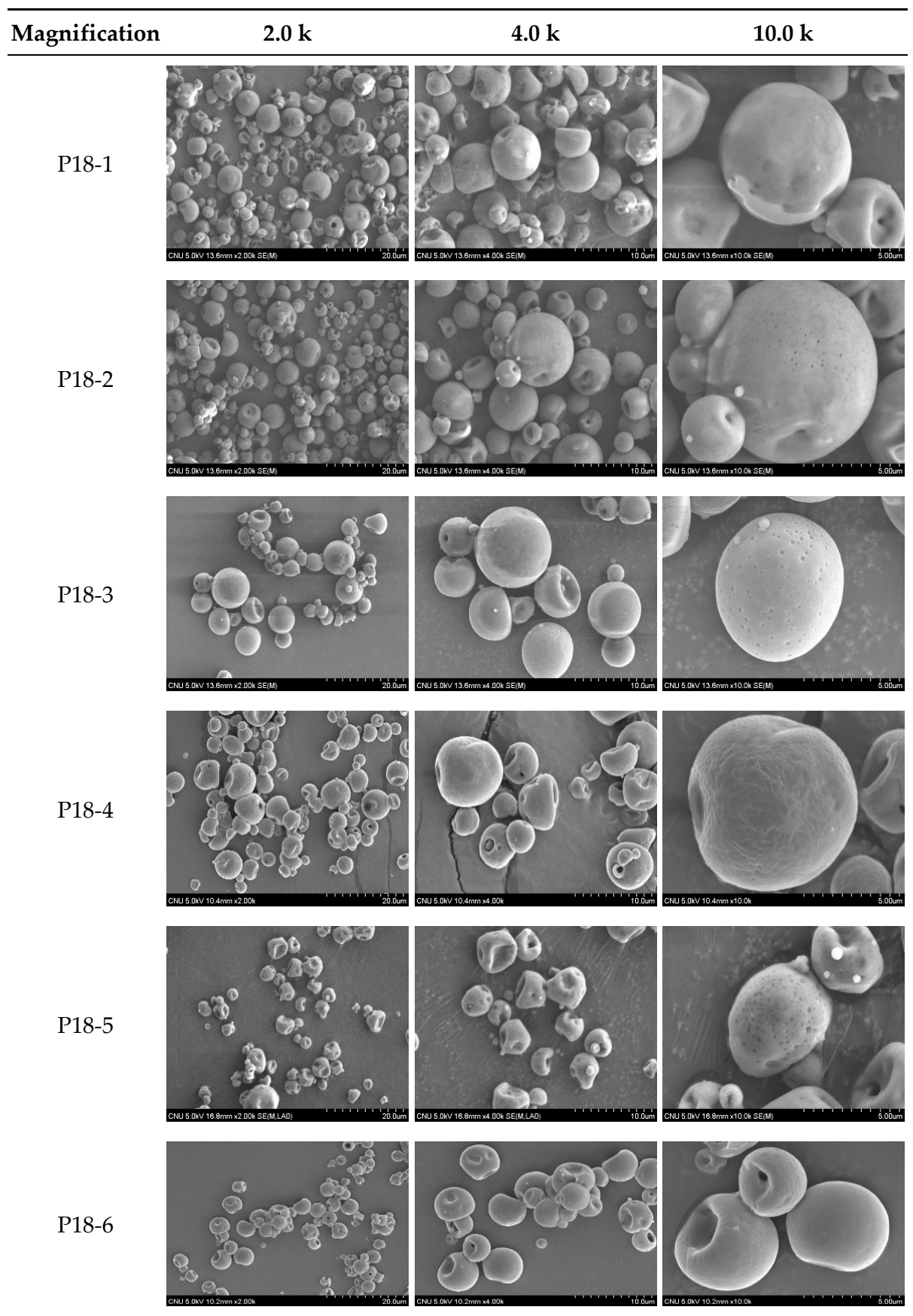

Figure 2. Cont. 


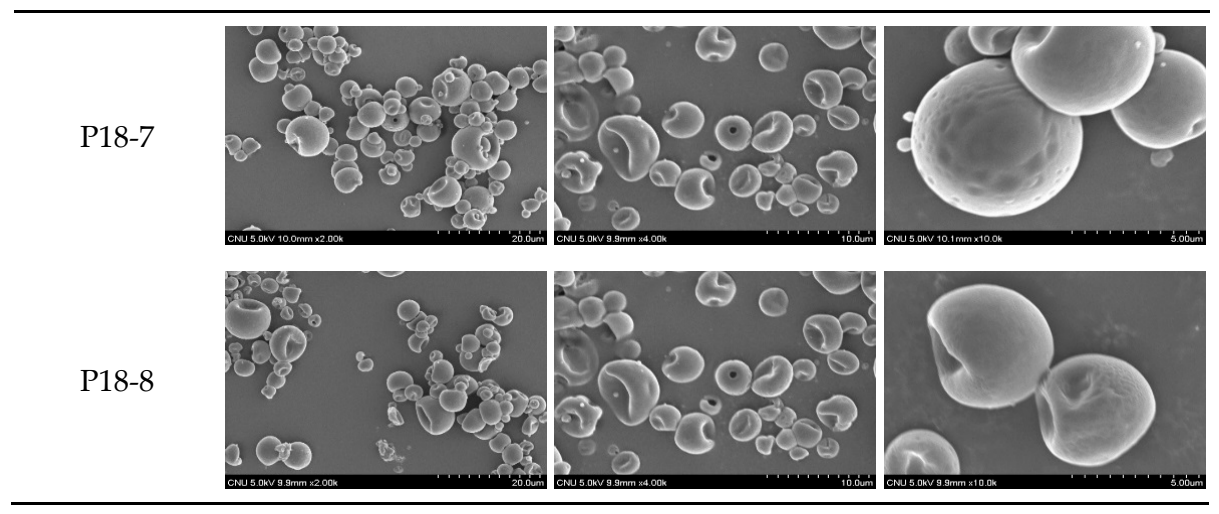

Figure 2. The effect of various spray drying condition on the morphology of spray-dried olive oil powder.

P18-8 was chosen as the best formulation, which had the smallest particle size before spray drying, showed the least amount of free oil and the highest amount of encapsulated oil, and showed relatively uniform morphology without dent. The morphology of omega-3 powder was shown in Figure 3. Even though unsaturated fatty acids do not solidify and exist in liquid form at low temperatures due to the structurally unstable nature [20], the morphology of omega-3 powder differed from powder containing olive oil. Comparing with formulation P18-8, only free-extractable oil content was increased significantly at $\mathrm{P}-\mathrm{O}$ formulation, and there was no significant difference on the others properties, contrastively having difference in morphology. The free-extractable oil content of $\mathrm{P}-\mathrm{O}$ formulation was about $33 \%$. And the encapsulated-oil content was approximately $18 \%$. The droplet size was about $310 \mathrm{~nm}$ to $320 \mathrm{~nm}$.

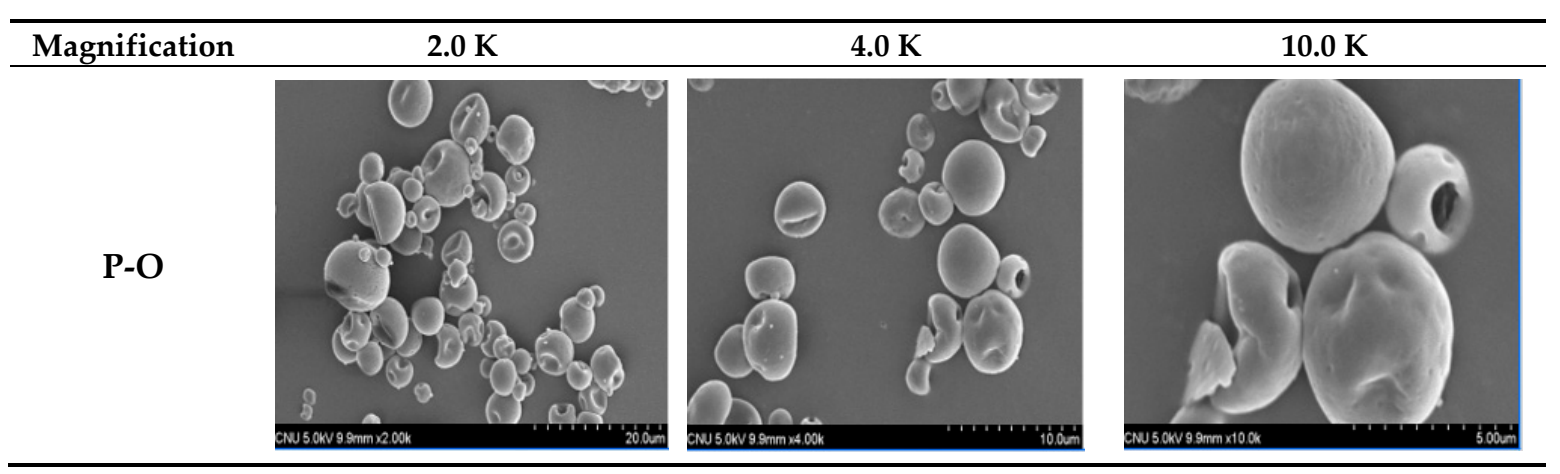

Figure 3. The SEM image of spray-dried omega-3 powder using $\gamma$-CD and hydrogenated lecithin with the optimal spray drying condition.

On the other hand, there are some publications about the structural characteristics of oil powders such as sardine oil and echium oil demonstrating a loss in crystallinity [21,22]. Taken together, P18 composed of $\gamma$-CD and hydrogenated lecithin was chosen for a further study. As $\gamma$-CD was increased, content of free oil was decreased and that of encapsulated oil was increased. In case of diluted emulsion (P18-6), the free oil content was lower than that of P18-4. The free oil content was decreased as spray-drying temperature was decreased (Table 5).

Table 5. The effect of the optimal spray drying condition on moisture amount, particle size and oil amount (free oil, encapsulated oil and total oil) of spray-dried omega-3 powder using $\gamma-\mathrm{CD}$ and hydrogenated lecithin $(n=3)$.

\begin{tabular}{ccccccc}
\hline Formular & Moisture (\%) & SE $(\mathbf{n m})$ & RE $(\mathbf{n m})$ & $\begin{array}{c}\text { Free Oil } \\
(\mathbf{g} / \mathbf{1 0 0} \mathbf{g})\end{array}$ & $\begin{array}{c}\text { Encapsulated } \\
\text { Oil }(\mathbf{g} / \mathbf{1 0 0} \mathbf{g})\end{array}$ & $\begin{array}{c}\text { Total Oil } \\
(\mathbf{g} / \mathbf{1 0 0} \mathbf{g})\end{array}$ \\
\hline $\mathrm{P}-\mathrm{O}$ & $2.63 \pm 0.21$ & $309.37 \pm 10.17$ & $326.70 \pm 9.53$ & $33.46 \pm 1.22$ & $18.57 \pm 0.69$ & $53.29 \pm 1.50$ \\
\hline
\end{tabular}


It is interesting that as atomization pressure was reduced (P18-8), the free oil content was the least and the encapsulated oil was the most. There was no significant difference between droplet size of secondary emulsion and reconstituted emulsion of spray dried omega-3 powder. This small difference between droplet size of SE and RE suggested that emulsion maintained enough stable and dried-particle was well dispersed. The concentration of EPA and DHA was reported in Table 6. Almost of DHA was remained after spray-drying, but just $80 \%$ of EPA was maintained. Maybe high temperature of spray-drying procedure affected EPA stability negatively and enhanced oxidation of EPA. It was correlated that high temperatures and the presence of oxygen may lead to an increased oxidation of long-chain polyunsaturated fatty acids so that a drying process at low temperatures (freeze-drying) is expected to be an alternative for the microencapsulation of fish oil [23,24]. So, the further study on reducing the lipid oxidation during spray-drying is needed. We prepared spray-dried emulsion powder containing olive oil, as an alternative to omega-3 fatty acids. The types of pharmaceutical excipients were investigated for spray-dried olive oil powder and $\gamma-C D$ and hydrogenated lecithin were chosen. Finally, spray-dried powder containing omega-3 fatty acids was successfully prepared.

Table 6. The content of eicosapentaenic acid (EPA) and docosahexaenoic acid (DHA) of spray-dried omega-3 powder using $\gamma$-CD and hydrogenated lecithin with the optimal spray drying condition $(n=3)$.

\begin{tabular}{ccc}
\hline & EPA & DHA \\
\hline Concentration $(\mathrm{mg} / \mathrm{mg}$ powder $)$ & $0.19 \pm 0.02$ & $0.22 \pm 0.01$ \\
Remaining percent $(\%)$ & $78.68 \pm 7.39$ & $98.23 \pm 4.38$ \\
\hline
\end{tabular}

\section{Conclusions}

The pharmaceutical excipients such as PVP, gelatin A, and gelatin B in the presence of hydrogenated lecithin or PEG40 glyceryl monostearate affected the formation of spray-dried powder containing olive oil due to the strong adsorption into hydrophobic material. We successfully prepared spray-dried omega-3 powder with $\gamma$-CD and hydrogenated lecithin and proposed the spray-drying conditions for scale-up, subsequently, this spray-dried omega-3 powder could be a new ingredient for new functional foods. In successive study, the change of crystallinity and polymorphism of spray-dried omega-3 powders will be examined. In addition, omega-3 powder will be prepared using a mixture of silica-based adsorbents and $\gamma$-CD for considering the cost for commercialization.

Supplementary Materials: The following are available online at http:/ / www.mdpi.com/2076-3417/9/6/1177/ s1.

Author Contributions: Individual contributions was as like this "methodology, Y.-G.N., M.K., H.-K.L.; formal analysis, H.W.H.; writing — original draft preparation, C.-J.H.; writing—review and editing, C.-W.C.".

Acknowledgments: This research was supported by the research fund of Chungnam National University.

Conflicts of Interest: The authors declare no conflict of interest.

\section{References}

1. Hung, P.; Kaku, S.; Yunoki, S.; Ohkura, K.; Gu, J.Y.; Ikeda, I.; Sugano, M.; Yazawa, K.; Yamada, K. Dietary effect of EPA-rich and DHA-rich fish oils on the immune function of Sprague-Dawley rats. Biosci. Biotechnol. Biochem. 1999, 63, 135-140. [CrossRef]

2. Christensen, K.L.; Pedersen, G.P.; Kristensen, H.G. Physical stability of redispersible dry emulsions containing amorphous sucrose. Eur. J. Pharm. Biopharm. 2002, 53, 147-153. [CrossRef]

3. Conquer, J.A.; Roelfsema, H.; Zecevic, J.; Graham, T.E.; Holub, B.J. Effect of exercise on FA profiles in n-3 FA-supplemented and-non supplemented premenopausal women. Lipids 2002, 37, 947-951. [CrossRef] [PubMed] 
4. Dollo, G.; Le Corre, P.; Guèrin, A.; Chevanne, F.; Burgot, J.L.; Leverge, R. Spray-dried redispersible oil-in-water emulsion to improve oral bioavailability of poorly soluble drugs. Eur. J. Pharm. Sci. 2003, 19, 273-280. [CrossRef]

5. Humberstone, A.J.; Charman, W.N. Lipid-based vehicles for the oral delivery of poorly water soluble drugs. Adv. Drug Deliv. Rev. 1997, 25, 103-128. [CrossRef]

6. Jang, D.J.; Jeong, E.J.; Lee, H.M.; Kim, B.C.; Lim, S.J.; Kim, C.K. Improvement of bioavailability and photostability of amlodipine using redispersible dry emulsion. Eur. J. Pharm. Sci. 2006, 28, 405-411. [CrossRef] [PubMed]

7. Schrooyen, P.M.; van der Meer, R.; De Kruif, C.G. Microencapsulation: Its application in nutrition. Proc. Nutr. Soc. 2001, 60, 475-479. [CrossRef]

8. Shah, A.V.; Serajuddin, A.T. Development of solid self-emulsifying drug delivery system (SEDDS) I: Use of poloxamer 188 as both solidifying and emulsifying agent for lipids. Pharm. Res. 2012, 29, 2817-2832. [CrossRef]

9. Tan, A.; Rao, S.; Prestidge, C.A. Transforming lipid-based oral drug delivery systems into solid dosage forms: An overview of solid carriers, physicochemical properties, and biopharmaceutical performance. Pharm. Res. 2013, 30, 2993-3017. [CrossRef]

10. Klinkesorn, U.; Sophanodora, P.; Chinachoti, P.; Decker, E.A.; McClements, D.J. Characterization of spray-dried tuna oil emulsified in two-layered interfacial membranes prepared using electrostatic layer-by-layer deposition. Food Res. Int. 2006, 39, 449-457. [CrossRef]

11. Araujo, P.; Nguyen, T.T.; Frøyland, L.; Wang, J.; Kang, J.X. Evaluation of a rapid method for the quantitative analysis of fatty acids in various matrices. J. Chromatogr. A 2008, 1212, 106-113. [CrossRef] [PubMed]

12. Vestland, T.L.; Jacobsen, Ø.; Sande, S.A.; Myrset, A.H.; Klaveness, J. Characterization of omega-3 tablets. Food Chem. 2016, 197, 496-502. [CrossRef] [PubMed]

13. Christensen, K.L.; Pedersen, G.P.; Kristensen, H.G. Preparation of redispersible dry emulsions by spray drying. Int. J. Pharm. 2001, 212, 187-194. [CrossRef]

14. Hansen, T.; Holm, P.; Rohde, M.; Schultz, K. In vivo evaluation of tablets and capsules containing spray-dried o/w-emulsions for oral delivery of poorly soluble drugs. Int. J. Pharm. 2005, 293, 203-211. [CrossRef]

15. Rowe, R. Handbook of Pharmaceutical Excipients, 7th ed.; Pharmaceutical Press: London, UK, 2006.

16. Buttini, F.; Soltani, A.; Colombo, P.; Marriott, C.; Jones, S.A. Multilayer PVA adsorption onto hydrophobic drug substrates to engineer drug-rich microparticles. Eur. J. Pharm. Sci. 2008, 33, 20-28. [CrossRef] [PubMed]

17. Ahn, J.H.; Kim, Y.P.; Seo, E.M.; Choi, Y.K.; Kim, H.S. Antioxidant effect of natural plant extracts on the microencapsulated high oleic sunflower oil. J. Food Eng. 2008, 84, 327-334. [CrossRef]

18. Sheu, T.Y.; Rosenberg, M. Microstructure of microcapsules consisting of whey proteins and carbohydrates. J. Food Sci. 1998, 63, 491-494. [CrossRef]

19. Walton, D.E. The morphology of spray-dried particles: A qualitative view. Dry Technol. 2000, 18, $1943-1986$. [CrossRef]

20. Lee, J.H. Polyunsaturated Fatty Acids in Children. Pediatric Gastroenterol. Hepatol. Nutr. 2013, 16, $153-161$. [CrossRef]

21. Vishnu, K.V.; Chatterjee, N.S.; Ajeeshkumar, K.K.; Lekshmi, R.G.K.; Tejpal, C.S.; Mathew, S.; Ravishankar, C.N. Microencapsulation of sardine oil: Application of vanillic acid grafted chitosan as a bio-functional wall material. Carbohydr. Polym. 2017, 174, 540-548. [CrossRef] [PubMed]

22. Azizi, M.; Kierulf, A.; Connie Lee, M.; Abbaspourrad, A. Improvement of physicochemical properties of encapsulated echium oil using nanostructured lipid carriers. Food Chem. 2018, 246, 448-456. [CrossRef] [PubMed]

23. Alamilla-Beltrán, L.; Chanona-Pérez, J.J.; Jiménez-Aparicio, A.R.; Gutiérrez-López, G.F. Description of morphological changes of particles along spray drying. J. Food Eng. 2005, 67, 179-184. [CrossRef]

24. Gangurde, A.B.; Ali, M.T.; Pawar, J.N.; Amin, P.D. Encapsulation of vitamin E acetate to convert oil to powder microcapsule using different starch derivatives. J. Pharm. Investig. 2017, 47, 559-574. [CrossRef]

(C) 2019 by the authors. Licensee MDPI, Basel, Switzerland. This article is an open access article distributed under the terms and conditions of the Creative Commons Attribution (CC BY) license (http:/ / creativecommons.org/licenses/by/4.0/). 